\title{
Avaliação histológica da próstata de cães adultos sexualmente intactos
}

\author{
[Prostatic histological evaluation in adult not castrated dogs] \\ C.E. Fonseca Alves ${ }^{1}$, M.B.R. Faleiro ${ }^{2}$, R. Laufer Amorim ${ }^{3}$, V.M.B.D. De Moura ${ }^{4 *}$ \\ ${ }^{1}$ Aluno de graduação - Bolsista IC - EV-UFG - Goiânia, GO \\ ${ }^{2}$ Aluna de pós-graduação - Bolsista CNPq - EV-UFG, Goiânia, GO \\ ${ }^{3}$ Faculdade de Medicina Veterinária e Zootecnia - UNESP - Botucatu, SP \\ ${ }^{4}$ Escola de Veterinária - UFG \\ Caixa Postal 131 \\ 74690-900 - Goiânia, GO
}

\begin{abstract}
RESUMO
Avaliou-se histologicamente a próstata de 30 cães adultos e idosos sexualmente intactos que apresentavam ou não sintomatologia clínica de doença prostática, e verificou-se a incidência de possíveis alterações da glândula. Dentre as alterações encontradas, a hiperplasia prostática benigna constituiu o diagnóstico mais comum, 85,6\% ( $\mathrm{n}=24)$, seguida por prostatite crônica, $64,3 \%(\mathrm{n}=18)$, displasia do epitélio glandular, 42,8\% ( $\mathrm{n}=12)$, atrofia do epitélio glandular, 39,3\% $(\mathrm{n}=11)$, infiltrado inflamatório focal, $25 \%(n=7)$, dilatação glandular focal, 21,4\% $(n=6)$, prostatite aguda, 7,1\% (n=2), metaplasia escamosa, 3,6\%, $(n=1)$, metástase de neoplasia sistêmica, 3,6\% $(n=1)$ e abscesso prostático, 3,6\% $(n=1)$. Como em muitos casos os cães são assintomáticos, ressalta-se a importância da realização rotineira de exames clínicos específicos, como o toque retal e a ultrassonografia, para o diagnóstico precoce e o tratamento das afecções prostáticas.
\end{abstract}

Palavras-chave: cão, doença prostática, glândula sexual acessória

\begin{abstract}
The prostates of 30 not castrated old dogs with or without clinical symptoms of prostatic disease were histologically evaluated. It was observed the incidence of possible changes in the gland. Among the changes, benign prostatic hyperplasia (BPH) was the most common diagnosis, accounting for $85.6 \%$ $(n=24)$, followed by chronic prostatitis, $64.3 \%(n=18)$, dysplasia of the glandular epithelium, $42.8 \%$ $(n=12)$, atrophy of the glandular epithelium, $39.3 \%(n=11)$, focal inflammatory infiltrate, $25 \%(n=7)$, focal glandular dilation, $21.4 \%(n=6)$, acute prostatitis, $7.1 \%(n=2)$, squamous metaplasia, $3.6 \%(n=1)$, metastasis of systemic neoplasia, 3.6\% (n=1), and prostatic abscess, $3.6 \%(n=1)$. Because the lack of symptoms in most of dogs with prostatic changes, the specific clinic exams in routine, as rectal palpation and ultrasonography, are very important to early diagnosis and treatment of dogs with prostatic disease.
\end{abstract}

Keywords: dog, prostatic disease, accessory sexual gland.

\section{INTRODUÇÃO}

A próstata canina é sede de diversas afecções que constituem problema comum em cães adultos e idosos (Purswell et al., 2000). A estreita relação anatômica entre a próstata, a uretra proximal e a bexiga urinária reflete a elevada frequência de

Recebido em 15 de fevereiro de 2009

Aceito em 7 de maio de 2010

*Autor para correspondência (corresponding author)

E-mail: vdmoura@vet.ufg.br afecções prostáticas, devido à infecção ascendente. Outra via de contaminação é a hematógena (Barsanti e Finco, 1992) e, muito menos comuns, mas possíveis, são as difusões renais, testiculares, epididimárias e peritoneais (Rodrigues et al., 1998).

A hiperplasia prostática benigna (HPB) ocorre em cães adultos e idosos, sendo considerada a 
alteração mais comum da próstata canina. Compreende aumento progressivo e induzido por hormônios, sendo que $100 \%$ dos cães adultos inteiros desenvolvem evidências histológicas de hiperplasia com o avançar da idade (Johnston et al., 2000).

A prostatite aguda compreende uma inflamação focal ou difusa, supurativa, com acúmulo de exsudato no lúmen glandular, presença de infiltrado polimorfonuclear e destruição do epitélio acinar, podendo haver comprometimento do estroma (De Moura, 2004). Processos crônicos podem se desenvolver de forma insidiosa e apresentar episódios de inflamação aguda. Abscessos prostáticos constituem forma severa de prostatite crônica, contendo quantidades variáveis de exsudato purulento acumulado no interior do parênquima glandular, sendo este envolto por uma cápsula de tecido conjuntivo (Dorfman e Barsanti, 1995; Purswell et al., 2000).

Cistos prostáticos são cavidades encapsuladas assépticas, preenchidas por fluido, comumente localizadas no parênquima prostático em decorrência do acúmulo de secreções prostáticas e resultantes da obstrução de ductos. Podem ainda apresentar-se em localização paraprostática, neste caso, sem comunicação com a próstata. Pode ocorrer contaminação dos cistos, resultando em formação de abscessos. A metaplasia escamosa prostática ocorre devido ao hiperestrogenismo exógeno ou endógeno que, além da metaplasia, também provoca estase secretória e, juntamente com a lesão epitelial, predispõem à formação de cistos, prostatites e abscessos (Dorfman e Barsanti, 1995; Johnston et al., 2000).

Neoplasias prostáticas são raras e ressaltadas com maior freqüência em cães adultos e idosos. Os tipos mais comuns são adenocarcinoma e carcinoma indiferenciado (Johnston et al., 2000; Purswell et al., 2000). A fase pré-maligna do câncer prostático corresponde à displasia ductoacinar ou neoplasia intraepitelial prostática (PIN), que compreende focos únicos ou múltiplos de proliferação intra-acinar, porém sem invasão da membrana basal (Waters et al., 1998; Leav et al., 2001).

O presente estudo teve por objetivo avaliar histologicamente a próstata de cães adultos e idosos sexualmente intactos que apresentassem ou não sintomatologia de doença prostática, verificando a incidência das possíveis alterações da glândula.

\section{MATERIAL E MÉTODOS}

Foram utilizadas 30 próstatas de cães com idade igual ou acima de três anos, selecionados aleatoriamente, sem restrição quanto à raça e porte, provenientes de rotina necroscópica e sem a necessidade de apresentarem histórico ou alterações clínicas de doença prostática.

A morfometria macroscópica compreendeu a pesagem e a mensuração do comprimento, largura e altura da próstata. Na sequência, foram realizados dois cortes transversais, com o intuito de facilitar a penetração do fixador e delimitar as porções cranial, média e caudal da glândula, especialmente quando esta se apresentava aumentada de volume. O material foi fixado em formol tamponado a $10 \%$, durante 72 horas, e, após este período, foi acondicionado e mantido em álcool $70 \%$ até o processamento. As próstatas foram processadas e incluídas em parafina, seguindo as técnicas de rotina de laboratório, com o material passando pelas fases de desidratação, clarificação, impregnação e inclusão. A partir dos blocos parafinados, confeccionaram-se cortes de $5 \mu \mathrm{m}$, que foram distendidos sobre lâminas histológicas e corados pela coloração de hematoxilina e eosina (HE).

A avaliação histológica foi realizada em microscópio óptico, e a classificação das alterações histomorfológicas seguiu os critérios adaptados de Ladds (1993) e Dorfman e Barsanti (1995). A análise histológica foi inicialmente realizada em menor aumento (50x), seguindo-se para os aumentos subsequentes (100x, 200x e 400x). O aumento de 50x auxiliava na visualização global do material, permitindo identificar áreas com diferentes padrões de lesão. Nos demais aumentos, avaliavam-se as estruturas epitelial e estromal e o infiltrado inflamatório, sendo que o aumento de 400x era utilizado para a verificação de atipia celular e nuclear, relação núcleo-citoplasma e presença de figuras de mitose. Ao final da avaliação do material, obteve-se a ocorrência de cada afecção prostática isoladamente, sendo a estatística descritiva, sob apresentação percentual, a forma de análise e apresentação dos resultados. Foram apuradas 
também as frequências de ocorrência de mais de um diagnóstico histológico no mesmo material.

\section{RESULTADOS}

Com relação à raça, 53,2\% (n=16) das amostras prostáticas pertenciam a cães sem raça definida (SRD) e 20\% (n=6) a cães da raça Pit Bull. Pastor Alemão, Pinscher, Cocker Spaniel e Rottweiler representaram $6,7 \% \quad(n=2)$ de cada raça.

Para a apresentação dos resultados referentes à morfometria macroscópica, as próstatas foram agrupadas de acordo com a classificação citohistológica e distribuídas em três grupos: normais $(n=2)$, com prostatite $(n=4)$ e hiperplásicas $(\mathrm{n}=24)$. A maior média de peso prostático ocorreu nas próstatas hiperplásicas $(1,87 \mathrm{~g} / \mathrm{kg} / \mathrm{PV})$. Para as normais e com prostatite, as médias de peso foram 0,77 e $0,91 \mathrm{~g} / \mathrm{kg} / \mathrm{PV}$, respectivamente. Ainda, entre as hiperplásicas, as epiteliais $(\mathrm{n}=10)$ apresentaram média de $2,53 \mathrm{~g} / \mathrm{kg}$ $\mathrm{PV}$, as complexas $(\mathrm{n}=6) \quad 1,97 \mathrm{~g} / \mathrm{kg} \quad \mathrm{PV}$ e as estromais $(\mathrm{n}=8) 1,06 \mathrm{~g} / \mathrm{kg} \mathrm{PV}$.

Quanto ao comprimento, largura e altura, as maiores médias ocorreram com as hiperplásicas, 3,$08 ; 2,80$ e $2,05 \mathrm{~cm}$, respectivamente, seguidas das com prostatite, 2,$61 ; 2,52$ e $1,6 \mathrm{~cm}$, e das normais 2,13; 1,98 e $1,88 \mathrm{~cm}$. Entre as hiperplásicas, as estromais apresentaram as menores médias, 2,63; 2,01 e 1,6cm, seguidas das epiteliais, 3,2; 3,08 e $2,67 \mathrm{~cm}$ e das complexas, 3,$43 ; 3,32$ e $2,55 \mathrm{~cm}$.

Duas próstatas normais foram classificadas considerando a presença de ácinos desenvolvidos, epitélio limitado a uma ou duas camadas de células e projeções digitiformes para o interior do lúmen, correspondendo a $6,7 \%$ do material analisado. Os demais $93,3 \%$ das glândulas apresentaram alterações $(n=28)$, sendo que, destes, 7,2\% contabilizaram apenas uma alteração, e $92,8 \%$ pelo menos duas alterações. As amostras histológicas avaliadas foram proporcionais ao tamanho prostático, ou seja, das próstatas maiores analisaram-se fragmentos das porções cranial, média e caudal.

Dentre as próstatas avaliadas, a HPB compreendeu a alteração de maior ocorrência, representando $85,6 \%(n=24)$ das lesões, seguidas por prostatite crônica, $64,3 \%(n=18)$, displasia do epitélio glandular, 42,8\% (n=12), atrofia do epitélio glandular, 39,3\% (n=11), infiltrado inflamatório focal, $25 \% \quad(n=7)$, dilatação glandular focal, 21,4\% ( $\mathrm{n}=6)$, prostatite aguda, $7,1 \%(n=2)$, metaplasia escamosa, 3,6\% ( $n=1)$, infiltração neoplásica, 3,6\% (n=1) e abscesso, $3,6 \%(n=1)$.

As hiperplasias foram classificadas em epitelial cística, epitelial papilífera e estromal, destacando que, em alguns casos, houve associação entre essas. Devido a isso, o percentual de ocorrência das diferentes formas histológicas de HPB foi maior que $100 \%$, visto que cada tipo foi contabilizado isoladamente.

Para a classificação da hiperplasia estromal (Fig. 1A), a mais frequente deste estudo $(58,3 \%)$, considerou-se a proliferação do estroma fibroso ou muscular, associada, com frequência, à atrofia glandular e infiltrado inflamatório mononuclear. Classificou-se a forma epitelial cística quando o epitélio glandular cúbico se apresentou hiperplásico e com formação de grandes cavidades císticas (Fig. 1B). Esse tipo correspondeu a $45,8 \%$ das lesões hiperplásicas. Caracterizou-se hiperplasia epitelial papilífera quando da múltipla projeção digitiforme do epitélio glandular ao lúmen (Fig. 1C), com aumento do número de camadas de células secretoras, correspondendo este tipo a $29,2 \%$ das HPB.

Considerando apenas os casos de associação entre hiperplasias $(n=8)$, que ocorreram em $33,3 \%$ dos diagnósticos de HPB $(n=24)$, e os critérios para diagnóstico dessas, verificou-se que a concomitância das formas cística e estromal correspondeu a $50 \%$, e a estromal e papilífera, assim como a cística e papilífera, representaram $25 \%$ cada, com formas hiperplásicas concomitantes. A associação entre os tipos epitelial e estromal é denominada hiperplasia complexa e correspondeu a $75 \%$ das associações de HPB diagnosticadas neste estudo.

Para a caracterização de prostatite crônica, observada em 64,3\% das glândulas com lesão, avaliou-se a presença de infiltrado inflamatório predominantemente mononuclear (linfócitos, plasmócitos e macrófagos), moderado ou acentuado, no interstício glandular, este muitas vezes acompanhado de atrofia glandular (Fig. 1D). 


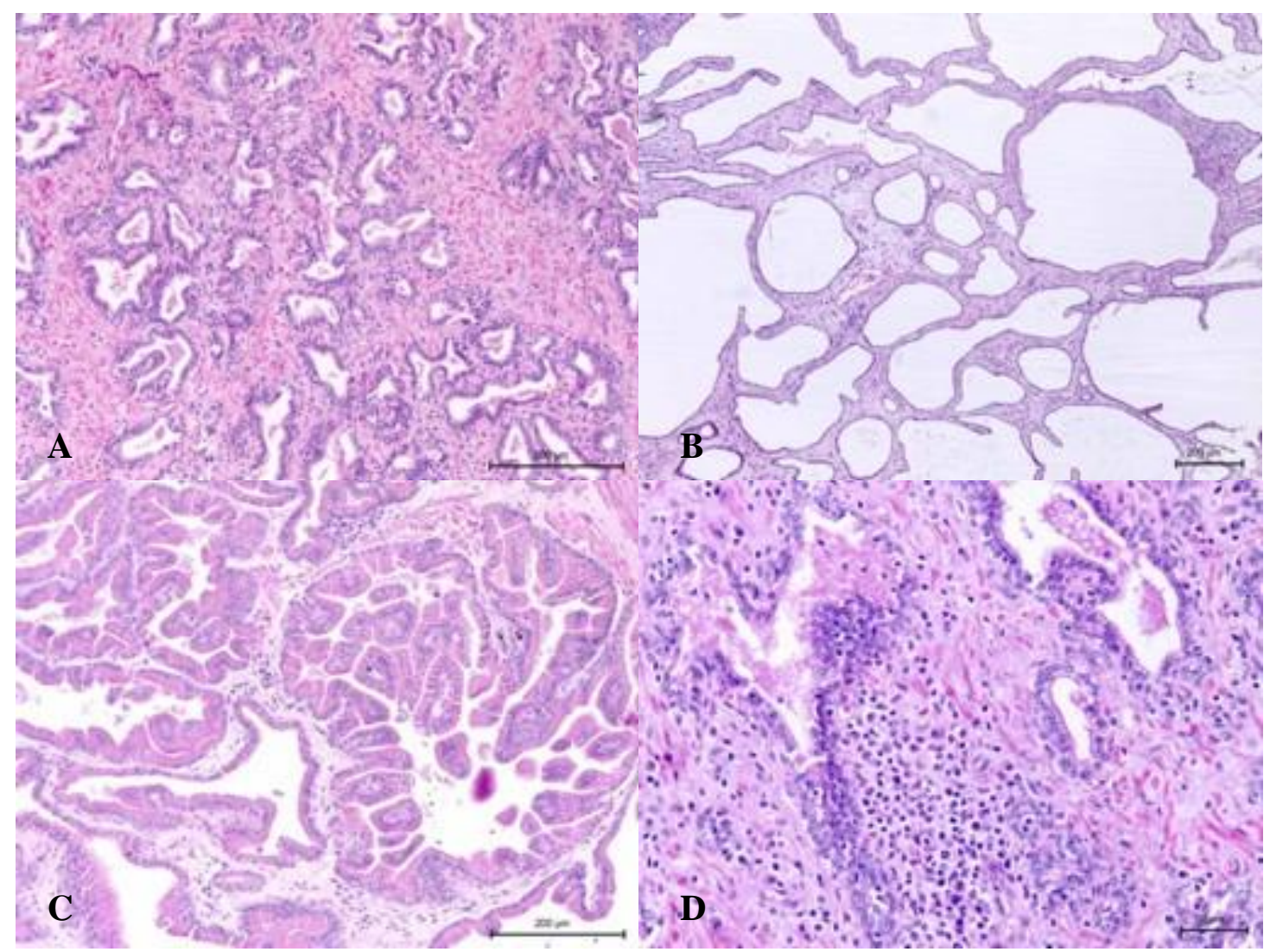

Figura 1. Cão. Fotomicrografias prostáticas. A) Hiperplasia estromal. B) Hiperplasia epitelial cística. C) Hiperplasia epitelial papilífera. D) Área de displasia epitelial discreta associada infiltrado inflamatório mononuclear periacinar e atrofia glandular. HE.

Foram constatados focos de displasia do epitélio glandular $(42,8 \%)$ que, na maioria dos casos, encontravam-se acompanhados de intensa infiltração leucocitária mononuclear intersticial periacinar. Observou-se atrofia do epitélio glandular prostático $(39,3 \%)$, relacionada principalmente à hiperplasia estromal e ao infiltrado inflamatório.

O infiltrado inflamatório focal correspondeu a $25 \%$ das próstatas, sendo predominantemente mononuclear. Verificaram-se $21,4 \%$ de dilatação glandular focal que não correspondia a um quadro de hiperplasia cística nem a um cisto de retenção, assim admitiu-se que essas alterações corresponderam aos estágios iniciais de hiperplasia cística. Casos de prostatite aguda representaram $7,1 \%$ dos diagnósticos. Microscopicamente, observaram-se hemorragia acentuada, hiperplasia cística, displasia epitelial e acentuado infiltrado polimorfonuclear intraacinar. Observada em menor frequência, a metaplasia escamosa representou $3,6 \%$ das alterações prostáticas catalogadas, ressaltando sua ocorrência em um cão idoso, com hiperplasia cística, displasia epitelial acentuada e a próstata pesando $6,25 \mathrm{~g} / \mathrm{kg} / \mathrm{PV}$. Na avaliação histológica das 30 próstatas, não foi observada neoplasia prostática primária, no entanto, uma glândula $(3,6 \%)$ apresentou infiltração neoplásica por linfoma. Verificou-se abscesso prostático em $3,6 \%$ das próstatas, associado à prostatite aguda.

\section{DISCUSSÃO}

Da mesma forma como já haviam descrito Purswell et al. (2000) e Teske et al. (2002), os resultados deste estudo confirmam a próstata de cães adultos e idosos como sede de diversas afecções, especialmente as HPB e as prostatites. Neste contexto, ressalta-se a importância da avaliação rotineira da próstata de cães dessas faixas etárias que não apresentam sintomatologia clínica de doença prostática, visto que a maior parte dos animais desta pesquisa se apresentava 
assintomática em relação a essas afecções, fato também destacado por Chew (1997).

A partir da morfometria macroscópica relacionada ao diagnóstico histológico, foi possível constatar que próstatas com hiperplasia epitelial apresentam peso maior quando comparadas àquelas normais, com hiperplasia estromal, complexa e com prostatites. Apesar de não terem agrupado os animais da mesma forma, Zirkin e Strandberg (1984) encontraram padrão semelhante, visto que grupos com cães portadores de hiperplasia demonstraram média de peso maior que aqueles com órgão de histologia inalterada. De Moura (2004), ao utilizar metodologia semelhante à deste estudo, também obteve maior peso prostático no grupo de cães com HPB epitelial. A morfometria macroscópica ainda revelou que próstatas hiperplásicas apresentam comprimento, largura e altura maiores em relação às com prostatite e normais, o que também foi relatado por Krawiec (1989) e Di Santis (2003).

Krawiec e Heflin (1992) e Chew (1997) observaram maior incidência de doença prostática em cães das raças Pastor Alemão e Dobermann Pinscher. Neste estudo, as lesões predominaram em animais sem raça pura, os SRD, entretanto, a segunda maior incidência de afecção prostática ocorreu em cães da raça Pit Bull, que ainda não foi citada como raça de alta ocorrência ou predisposta a tais enfermidades. Vale ressaltar que o fator racial é relevante quando se consideram lesões que envolvem a próstata canina, contudo, estudos realizados em diferentes países refletem padrões raciais regionais, mas todos são unânimes em considerar o avançar da idade e a ação hormonal os maiores responsáveis pela gênese das afecções prostáticas no cão (Barsanti e Finco, 1992; Purswell et al., 2000; De Moura, 2004).

A maioria das próstatas com lesão deste estudo $(92,8 \%)$ apresentou pelo menos duas alterações distintas, aspectos já relatados por Barsanti e Finco (1992), Krawiec e Heflin (1992), Di Santis (2003) e De Moura (2004). Oliveira et al. (2007) encontraram alterações em $100 \%$ das glândulas, mas somente $22 \%$ dessas apresentaram mais de uma alteração. A dessemelhança entre os trabalhos acerca dos diagnósticos concomitantes justifica-se pela da metodologia aplicada em ambos. No trabalho de Oliveira et al. (2007), foi coletado apenas um fragmento prostático, independente do tamanho da próstata e, neste, as amostras contemplaram diferentes porções da glândula, especialmente naquelas de maior tamanho, demonstrando a importância da avaliação prostática seriada e completa.

A HPB consistiu a alteração mais frequente na avaliação histológica da próstata de cães com idade acima de três anos. Este resultado confirma as observações de Johnston et al. (2000), que descreveram a HPB como uma alteração comum em cães adultos e idosos. Dentre as hiperplasias, a estromal foi a de maior ocorrência, resultado descrito anteriormente por De Moura (2004). Quando considerada a concomitância de mais de um tipo de HPB, obteve-se menor ocorrência, $33,3 \%$, em relação ao trabalho realizado por De Moura (2004), 58\%, sendo a diferença justificada pelo maior número de próstatas avaliadas no referido estudo.

No cão, a prostatite pode ser aguda ou crônica e estar ou não associada a outras alterações prostáticas como a HPB (De Marzo et al., 1999; Di Santis, 2003). Ambos os tipos de prostatite foram diagnosticados nas próstatas deste estudo, especialmente em associação com a HPB. Ainda, a prostatite crônica constituiu $\mathrm{O}$ segundo diagnóstico de maior ocorrência e, independente da apresentação única ou concomitante, o resultado obtido assemelha-se aos verificados por Di Santis (2003) e Oliveira et al. (2007). Destaca-se que o percentual de prostatite concomitante a outras alterações prostáticas é sempre superior ao observado nos casos isolados. Nesse contexto, De Marzo et al. (1999) referemse ao processo inflamatório frequentemente acompanhado por anormalidades da proliferação celular. Ainda, Lee et al. (1997) acrescentam que, dentre os fatores ambientais que contribuem para o desenvolvimento da hiperplasia, o infiltrado inflamatório mononuclear não relacionado a microrganismos pode ser considerado fator somático, visto que essas células produzem interleucinas que estimulam a formação de matriz pela síntese de colágeno, assim como promovem a proliferação das células estromais e epiteliais da próstata. CHEW (1997) também citou que a HPB predispõe a glândula ao desenvolvimento de prostatite bacteriana e à formação de abscessos. 
Displasia epitelial glandular foi constatada em $42,8 \%$ das próstatas com lesão, sendo esta geralmente em ácinos com intensa infiltração leucocitária adjacente, assim como observado por Laufer Amorim (2001). Ainda, atrofia epitelial foi verificada em $39,3 \%$ das amostras com alteração, esta muitas vezes associada à hiperplasia estromal e infiltrado inflamatório mononuclear periacinar, o que também foi constatado por Di Santis (2003).

Devido à grande importância das células inflamatórias, classificou-se o infiltrado inflamatório mononuclear moderado ou acentuado no interstício como prostatite crônica e infiltrados focais foram avaliados separadamente, considerando que em muitos casos somente o infiltrado se fez presente no material avaliado, correspondendo a $25 \%$ das alterações. Casos de prostatite aguda representaram $7,1 \%$ das amostras, caracterizados por ácinos repletos de exsudato inflamatório, sendo este predominantemente polimorfonuclear e havendo ainda áreas de destruição do epitélio acinar, o que também foi encontrado por De Moura (2004).

A metaplasia escamosa do epitélio glandular está associada a fatores hormonais e frequentemente leva ao acúmulo de líquido intraluminal e formação de cisto de retenção (Vannucchi et al., 1997), além de serem consideradas lesões prémalignas para processos neoplásicos prostáticos primários (Weinberg, 1996; Waters et al., 1998). No estudo em questão, metaplasias corresponderam a 3,6\% das lesões prostáticas, estas frequentemente em próstatas hiperplásicas e com displasia epitelial acinar, mas sem evidências microscópicas de neoplasia prostática primária.

\section{CONCLUSÕES}

Conclui-se que as afecções prostáticas são de grande importância em cães adultos e idosos devido à alta ocorrência, especialmente da HPB e da prostatite crônica. Como em muitos casos os cães são assintomáticos, ressalta-se a importância da realização de exames clínicos de rotina específicos, como o toque retal e a ultrassonografia, para o diagnóstico precoce e o tratamento das afecções prostáticas.

\section{REFERÊNCIAS BIBLIOGRÁFICAS}

BARSANTI, J.A.; FINCO, D.R. Moléstias prostáticas do cão. In: ETTINGER, S.J. Tratado de Medicina Interna Veterinária. 3.ed. São Paulo: Malone, 1992, p.1941-1963.

CHEW, D.J. An overview of prostatic disease. Comp. Cont. Educ. Pract. Vet., v.19, p.80-85, 1997.

DE MARZO, A.M.; COFFEY, D.S.; NELSON, E.G. New concepts in tissue specificity for prostate cancer and benign prostatic hyperplasia. Urology, v.53, p.29-40, 1999.

DE MOURA, V.M.B.D. Estudo laboratorial, anatomopatológico, e imunoistoquímico da próstata de cães adultos. 2004. 144f. Tese (Doutorado) - Faculdade de Medicina Veterinária e Zootecnia, Universidade Estadual Paulista, Botucatu.

DI SANTIS, G.W. Estudo morfológico, morfométrico e imunoistoquímico de próstatas caninas normais e hiperplásicas. 2003. $128 \mathrm{f}$. Dissertação (Mestrado) - Faculdade de Medicina Veterinária e Zootecnia, Universidade Estadual Paulista, Botucatu.

DORFMAN, M.; BARSANTI, J. Disease of the canine prostatic gland. Comp. Cont. Educ. Pract. Vet., v.17, p.791-811, 1995.

JOHNSTON, S.D.; KAMOLPATANA, K.; ROOT-KUSTRITZ, M.V. et al. Prostatic disorders in dog. Anim. Rep. Sci., v.60, p.405$415,2000$.

KRAWIEC, D.R. Urologyc disorders of the geriatric dog. Vet. Clin. North Am. Small Anim. Pract., v.19, p.75-85, 1989.

KRAWIEC, D.R.; HEFLIN, D. Study of prostatic disease in dogs: 177 cases (1981-1986). J. Am. Vet. Med. Assoc., v.27, p.231-2343, 1992.

LADDS, P.W. The male genital system. In: JUBB, K.V.F.; KENNEDY, P.C.; PALMER, N. (Eds). Pathology of domestic animals. 4.ed. San Diego: Academic, 1993. v.3, p.471-529.

LAUFER AMORIM, R. Estudo clínico, laboratorial e anatomopatológico das próstatas de cães adultos. 2001. 116f. Dissertação (Doutorado) - Faculdade de Medicina Veterinária e Zootecnia, Universidade Estadual Paulista, Botucatu. 
LEAV, I.; SCHELLING, K.H.; ADAMS, J.Y. et al. Role of canine basal cells in prostatic post natal development, induction of hyperplasia, sex hormone stimulated growth and the ductal origin of carcinoma. Prostate, v.47, p.149-163, 2001.

LEE, I.; KOZLOWSKI, J.M.; GRAYHACK, J.T. Intrinsic and extrinsic factors controlling benign prostatic growth. Prostate, v.31, p.131$138,1997$.

OLIVEIRA, K.S.; ARAUJO, E.G.; SILVA, L.A.F. et al. Alterações prostáticas de cães adultos necropsiados na Escola de Veterinária da Universidade Federal de Goiás de maio a julho de 2004. Cienc. Anim. Bras., v.8, p.267-272, 2007.

PURSWELL, B.J.; PARKER, N.A.; FORRESTER, S.D. Prostatic diseases in dogs: a review. Vet. Med., p.315-321, 2000.

RODRIGUES, B.A.; BOHRER, J.L.; RODRIGUEZ, J.L. Abscesso prostático canino. Hora Vet., v.18, p.69-73, 1998.
TESKE, E.; NAAN, E.C.; VAN DIJK, E.M. et al. Canine prostate carcinoma: epidemiological evidence o fan increased risk in castrated dogs. Mol. Cell. Endocrinol., v.197, p.251-255, 2002.

VANNUCCHI, C.I.; VENTURA, P.C.F.; SATZINGERS, S. et al. Afecções prostáticas em cães: sinais clínicos, diagnóstico e tratamento. Clin. Vet., v.2, p.37-41, 1997.

WATERS, D.; SAKR, W.A.; HAYDEN, D.W. et al. Workgroup 4: Spontaneous prostate carcinoma in dogs and non human primates. Prostate, v.36, p.64-67, 1998.

WEINBERG, R.A. Molecular mechanisms of carcinogenesis. Sci. Am., v.4, p.1-12, 1996.

ZIRKIN, B.R.; STRANDBERG, J.D. Quantitative changes in the morphology of the aging canine prostate. Anat. Rec., v.208, p.207214, 1984. 